\title{
Analysis of Gravity Waves Generated at the Top of a Drainage Flow
}

\author{
SAMUEl ViANA AND ENRIC TERRADELlaS \\ AEMET, Barcelona, Spain \\ CARLOS YAGÜE \\ Departamento de Geofísica y Meteorología Universidad Complutense de Madrid, Madrid, Spain
}

(Manuscript received 17 March 2010, in final form 21 June 2010)

\begin{abstract}
Drainage or katabatic flows are common mesoscale circulations established as a result of differential radiative cooling of near-surface air masses in sloping terrain. The initial irruption of these flows, with sudden shifts in wind speed and direction, may result in vertical displacements of air parcels from their equilibrium position, which prove to be a common source of internal gravity waves. This paper illustrates this mechanism and describes the main features of the oscillations following the study of observational data gathered throughout one night during the Stable Atmospheric Boundary Layer Experiment in Spain 2006 (SABLES2006) field campaign. Pressure differences, measured by microbarometers set at different levels of a tower, help to interpret the evolution of other atmospheric variables, provide a detailed picture of the irruption of a drainage current, and reveal the formation of gravity waves at its top. The main parameters of the waves are derived from wavelet cross correlation of pressure time series, recorded by a surface array of microbarometers. The analysis yields, among other parameters, the horizontal component of the phase and group velocities of the gravity waves, which compare well with the velocity of irruption of the drainage current. Wavelet and other multiresolution techniques are also applied to sonic anemometer records to study the interaction between turbulence and larger-scale motions. The analysis shows evidence of heat flux divergence induced by the gravity waves, which may constitute a key factor for the vertical thermal profile in the nocturnal boundary layer (NBL) in situations of weak turbulence and important wave activity.
\end{abstract}

\section{Introduction}

In the absence of strong synoptic-scale forcing, when there is a weak horizontal pressure gradient, the structure and evolution of the nocturnal boundary layer (NBL) are dominated by mesoscale or even microscale conditions. Both regional and local circulations are driven mainly by surface heterogeneities, with the different scales of topographical features as the main forcing factor (Cuxart et al. 2007; Martínez et al. 2010). Drainage flows, also known as katabatic winds and density or gravity currents, are very common in virtually any sloping terrain. Even over flat land, drainage circulations originated by topographical features in the vicinity may

Corresponding author address: Samuel Viana, Delegación Territorial de AEMET en Cataluña, Arquitecte Sert s/n, 08005, Barcelona, Spain.

E-mail: svianaj@aemet.es be observed (Barry 1992; Maguire et al. 2006; Yagüe et al. 2007; Martínez and Cuxart 2009).

Observations of katabatic winds indicate a generally unsteady nature, even in the most quiescent conditions (Poulos et al. 2000, and references therein). This unsteady character, the shallow depth of these currents, and their dependence on small-scale features of the terrain topography prevent NWP or climate models from explicitly simulating these circulations with acceptable accuracy. As a consequence, the role of drainage flows in the evolution of the NBL conditions sometimes has to be parameterized (e.g., Terradellas and Cano 2007; Zammett and Fowler 2007).

From the early work of Fournet (1840), which explained the mechanism driving the mountain breeze in the Rhone valley, many studies have been devoted to drainage flows from different points of view: theoretical or observational works (e.g., Simpson 1982, 1997; Rottman and Linden 2001), numerical simulations (Thyer 1966; Parish 1984; Banta and Gannon 1995; Cuxart et al. 2007), 
and laboratory experiments in tanks (Ellison and Turner 1959; Simpson 1969; Simpson and Linden 1989; Patterson et al. 2006). Moreover, there have been several field campaigns with the study of katabatic flows as one of the main objectives: for example, the Atmospheric Studies in Complex Terrain (ASCOT) program, carried out in Colorado in the 1980s and early 1990s (Doran 1993; Poulos et al. 2000) or, more recently, the Vertical Transport and Mixing (VTMX) campaign (Doran et al. 2002).

The organization of these circulations at the scale of a basin, with the presence of slope and out-valley circulations and the possible formation of cold pools, is extremely complex. Its study usually has to be based on numerical simulations, as in Cuxart et al. (2007) for the island of Majorca or in Martínez et al. (2010) for the Duero basin, both in Spain. The coexistence of circulations at different scales and the three-dimensional character of the drainage flows lead to the existence of areas with important horizontal mass divergence/ convergence and, consequently, with relatively large values of downward/upward vertical velocity. Banta et al. (2007) state that these areas show an enhanced vertical transport that may be large compared to the background mixing that would occur without drainage flows. Cano and Terradellas (2008) discuss the importance of such vertical motions in the particular aspect of fog formation.

On the other hand, internal gravity waves (IGWs) may be important in the context of the NBL. These are oscillations inside a stably stratified layer, induced by buoyancy forces when an air parcel is vertically displaced. The vertical shifting forced by the terrain topography is generally considered as the main source of gravity waves in northern midlatitudes (McFarlane 1987). Poulos et al. (2000) consider that topographically induced gravity waves of some form develop whenever a stably stratified flow encounters a barrier. However, many other sources of gravity waves have been postulated: convection (Larsen et al. 1982; Beres 2004), geostrophic adjustment associated with unbalanced flow (Uccellini and Koch 1987), cold fronts (Gall et al. 1988; Fritts and Nastrom 1992; Ralph et al. 1999), and wind shear (Lalas and Einaudi 1976; Mastrantonio et al. 1976; Fritts 1982), among others. The present study analyses an event in which IGWs are apparently generated by the outbreak of a katabatic flow. Many studies report oscillations in katabatic flows (Gryning et al. 1985; Helmis and Papadopoulos 1996; Van Gorsel et al. 2003; Bastin and Drobinski 2005), but few authors mention the generation of gravity waves by katabatic flows, with Chemel et al. (2006) and Hertzog et al. (2008) being among them. Nappo et al. (2008) found traces of gravity waves a few minutes after the onset of a density current at a site. Their analysis focused on the impact of the wave on turbulence statistics and plume diffusion, but a possible relationship between the wave and the density current was not explored. This last point is interesting, and it will be one of the focusing aspects in this work. McNider (1982) had already introduced buoyancy in his theoretical model for drainage flows and predicted oscillations with the Brunt-Väisälä frequency. Poulos et al. $(2000,2007)$ theorized that gravity wave pressure perturbations are transmitted through the atmospheric column to the surface and, through altered horizontal pressure gradient forcing, to the surface-based katabatic flow.

As occurs with katabatic flows, the effects of gravity waves cannot be explicitly reproduced by global-scale NWP or climate models, or by mesoscale simulations, because of their low resolution. Like other subgrid-scale processes, they are commonly introduced in the physical parameterizations of the models. Different parameterization schemes have been developed for the different processes to be represented and types of gravity waves involved, such as orographic gravity wave drag (McFarlane 1987; Gregory et al. 1998; Scinocca and McFarlane 2000), gravity wave drag induced by subgridscale cumulus convection (Kershaw 1995; Bossuet et al. 1998; Chun and Baik 1998; Chun et al. 2001), and so on.

The IGWs can appear in the atmosphere in a very wide range of scales, and in the present work we are interested in those affecting the atmospheric boundary layer and scales associated with it. Several studies have been published on the interaction of gravity waves with turbulence in the atmospheric boundary layer (Stewart 1969; Finnigan et al. 1984; Finnigan 1988; Einaudi et al. 1989; Einaudi and Finnigan 1993). However, gravity waves are a complex phenomenon with a high level of variability and nonlinearity; the effects produced by a given wave propagating along an experimental site are hardly reproduced in the same way by other waves in the same location, let alone at other sites. Moreover, the range of temporal and spatial scales involved in wave motions is also affected by a number of additional mesoscale motions that often make the stable boundary layer (SBL) nonstationary over time scales of less than an hour (Mahrt 2007, 2010; Acevedo and Mahrt 2010). Some of these mesoscale structures are well identified, such as drainage currents, microfronts, or solitons, but others have an unknown origin, such as meandering motions (Belušić and Güttler 2010) or horizontal modes. Additionally, the largest turbulent eddies may present time scales similar to waves or mesoscale structures. In such cases, an explicit separation of turbulence, wave, and mesoscale motions is not feasible (Vickers and Mahrt 2003; Voronovich and Kiely 2007; Viana et al. 2009), which makes the mutual influences difficult to study. 
As a consequence of all these points, the presence of IGWs in stably stratified boundary layers and their interaction with turbulence is an open-ended question, which is not yet well understood. However, good knowledge in this field could better help us to learn some of the different physical processes taking place and their effects during stably stratified nights in midlatitudes. One of the main motivations of this work is the study of turbulent mixing in NBLs where IGWs are present, in situations with a weak synoptic-scale pressure gradient. Forecasting models (even mesoscale models) cannot accurately represent these situations, preventing the achievement of good simulations of important issues where an accurate evaluation of the turbulent mixing is necessary, such as minimum temperatures, low-level winds, fog episodes, or air-quality levels.

This work uses data gathered during a single night of the Stable Atmospheric Boundary Layer Experiment in Spain 2006 (SABLES2006) field campaign (Yagüe et al. 2007) to describe the irruption of a drainage flow on the site and the generation of gravity waves on its top. It aims to be an in-depth analysis of a gravity wave event associated with a drainage flow during the development of an SBL. It uses both traditional and not very extended data (such as those coming from high-resolution microbarometers installed near the surface and in a 100-m tower) in order to advance knowledge of the physical processes present in these situations and the origin of the waves formed, which are sometimes far from clear. Two modern multiscale tools have been used to achieve this objective: the wavelet transform (Torrence and Compo 1998; Terradellas et al. 2001) and multiresolution flux decomposition (MRFD; Howell and Mahrt 1997). The combination of both techniques seems to be very appropriate to study nonstationary regimes where turbulence and waves coexist. Furthermore, these methods considerably improve the evaluation of turbulent fluxes and kinetic energy, compared to the traditional eddycovariance calculations, especially when a spectral gap is found separating turbulence from larger scales, which results in a more accurate estimation of turbulent mixing in stable conditions. The focus is then put on the characteristics of these waves and their interaction with the turbulent regime. In section 2 a brief description of the experimental site and the available data is provided. Section 3 explains the multiscale methods applied to data analysis. In section 4 the night of $22-23$ June is analyzed in detail and the main results are shown. Some conclusions are stated in section 5 .

\section{Site and data collection}

The SABLES2006 field campaign (Yagüe et al. 2007; Viana et al.2009) took place between 19 June and 12 July
2006 at the Research Center for the Lower Atmosphere (CIBA in Spanish). The atmospheric laboratory is run by the University of Valladolid and the Spanish Meteorological Agency (AEMET). It is situated at $41^{\circ} 49^{\prime} \mathrm{N}$, $4^{\circ} 56^{\prime} \mathrm{W}, 840 \mathrm{~m}$ MSL, about $30 \mathrm{~km}$ northwest of the city of Valladolid, in the northern part of the Iberian Peninsula, in the upper Duero basin (San José et al. 1985). This basin is a broad plain with an average height of $800 \mathrm{~m}$ MSL, surrounded by mountain ranges over $2500 \mathrm{~m}$ MSL (Fig. 1a), with a narrow pass allowing the river to flow into the Atlantic. During nights with weak synoptic forcing, mountain-valley winds and a general westward drainage circulation are organized at a meso-beta scale (Cuxart 2008; Bravo et al. 2008). A smaller, quite flat and homogeneous plateau of nearly $800 \mathrm{~km}^{2}$ known as Montes Torozos rises about $40 \mathrm{~m}$ over the rest of the Duero basin. The CIBA is located in the middle of this plateau, more than $100 \mathrm{~km}$ away from the surrounding mountains. The terrain is covered by low open shrub land surrounded by crop fields, mainly autumn-sown cereal crops, with a roughness parameter of about $1.1 \mathrm{~cm}$ (San José et al. 1985).

The field campaign was designed to fill in some gaps detected during previous campaigns carried out at the same place (Cuxart et al. 2000), especially regarding the observation of IGWs. The laboratory's main facility is a 100-m mast, equipped with fast-response sonic anemometers and a set of conventional sensors that measure wind speed and direction, air temperature and relative humidity at different heights, soil temperature, and atmospheric pressure at the surface (see Table 1 for details). This instrumentation was installed by the Risoe National Laboratory in 2001 as part of a project to upgrade the tower, which had been active since the 1980s (San José et al. 1985; Cuxart et al. 2000; Conangla et al. 2008). In addition, six Paroscientific microbarometers especially intended for the detection and characterization of IGWs were installed during the campaign; three of them were set on the tower at 20,50, and $100 \mathrm{~m} \mathrm{AGL}$, and the remaining three were deployed at $1.5 \mathrm{~m} \mathrm{AGL}$ on the vertices of a triangle of approximately $200 \mathrm{~m}$ per

TABLE 1. Main instrumentation installed on the 100-m mast.

\begin{tabular}{llc}
\hline \hline \multicolumn{1}{c}{ Instrument } & \multicolumn{1}{c}{ Alt $(\mathrm{m})$} & $\begin{array}{c}\text { Sampling } \\
\text { rate }(\mathrm{Hz})\end{array}$ \\
\hline $\begin{array}{l}\text { Metek USA-1 sonic } \\
\text { anemometers }\end{array}$ & $3,19.6,96.6$ & 20 \\
Wind vanes & $9.6,34.6,74.6,98.6$ & 5 \\
Cup anemometers & $2.3,9.6,34.6,50,74.6,98.6$ & 5 \\
Platinum resistance & $2.3,10.5,20.5,35.5,97.5$ & 1 \\
$\quad$ thermometers & $20,50,100$ & 2 \\
Microbarometers & 10,97 & 5 \\
Humidity sensors & \multicolumn{1}{c}{ Her } \\
\hline
\end{tabular}




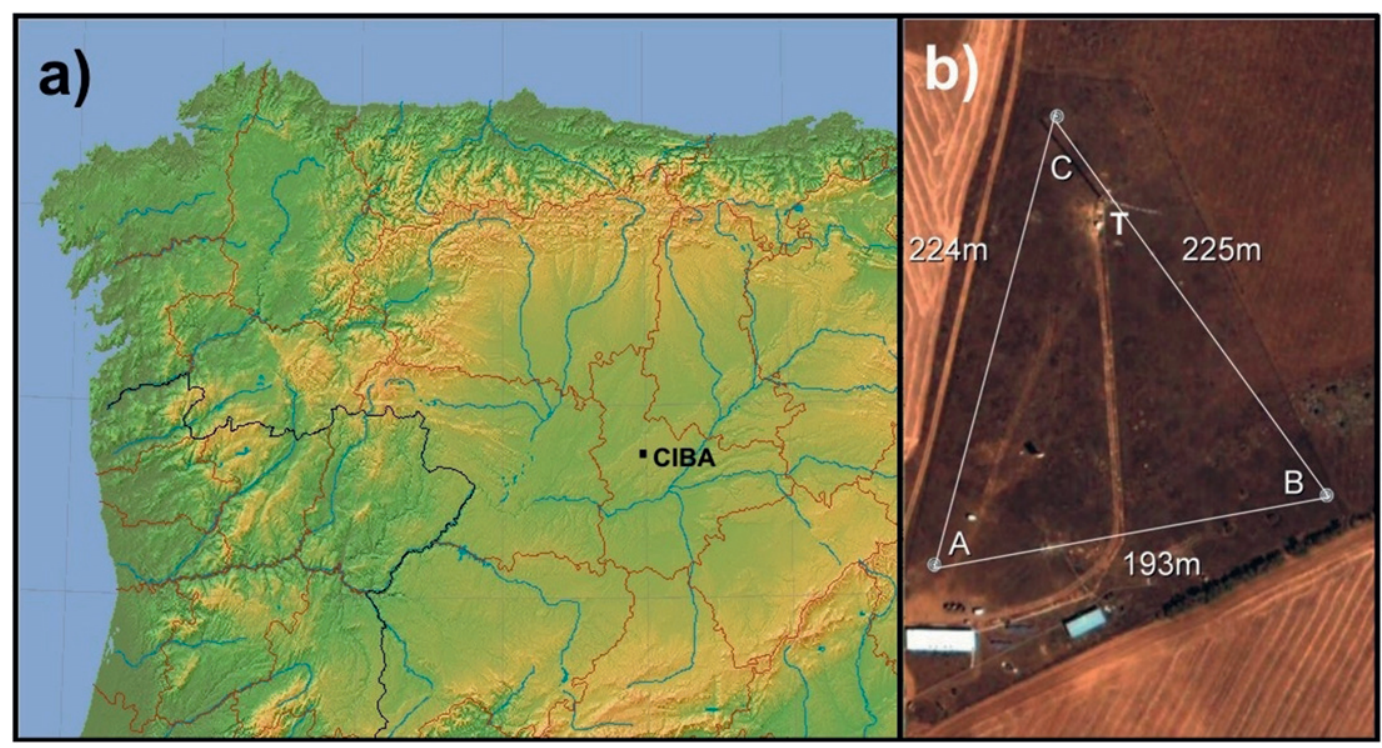

FIG. 1. (a) The position of the CIBA experimental site on the upper Spanish plateau, showing main topographic features, and (b) aerial image of the CIBA site, with the location of the 100-m tower (T) and the triangular array of microbarometers (A, B, C). Light colors in the upper left and lower right areas correspond to crop fields surrounding the CIBA site.

side (Fig. 1b). The devices were configured to measure the absolute pressure at a sampling rate of $2 \mathrm{~Hz}$ and a resolution of around $0.002 \mathrm{hPa}$. These values were set as a compromise between having a high enough sampling rate and the necessary resolution to register low-amplitude pressure perturbations (both parameters are inversely related in these quartz-based devices). The records of the microbarometers proved to be ideal for observing the propagation of wavelike structures and estimating the wave parameters (Viana et al. 2007, 2008, 2009).

Other data sources available during the campaign included wind and temperature data both from a Radio Acoustic Sounding System (RASS) sodar and tethered balloon soundings; however, these will not be used intensively in our study because of the poor quality or low availability of the data for the selected night.

\section{Multiscale methods}

\section{a. The wavelet transform}

Since the early 1990s, wavelet analysis (Daubechies 1992) has been widespread in different scientific fields. It was soon applied in fluid mechanics (Farge 1992) and, in particular, in oceanography and meteorology (Meyers et al. 1993). The wavelet transform provides an estimation of the time evolution of the amplitude (or the energy) of the different oscillations embedded in a time series of any magnitude. In the present work, wavelet techniques are applied to the identification and characterization of gravity waves, and other coherent structures, in time series of different boundary layer variables. Waveletbased methods are remarkably useful to analyze the different scales that are present and that play an active role in boundary layer dynamics. Furthermore, they allow investigation into the interaction between these scales.

Following Terradellas et al. (2001), who analyzed time series of different meteorological variables recorded at the CIBA atmospheric laboratory during the SABLES 98 field campaign (Cuxart et al. 2000), the energy density per time and scale unit of a real time series may be defined as

$$
e_{s, t}^{f}=\frac{2}{C_{\Psi}} \frac{\left|F_{s, t}\right|^{2}}{s^{2}}
$$

where $C_{\Psi}$ is a normalizing factor and $F_{s, t}$ is the wavelet transform of the time series $f$ at the scale $s$ and time $t$, defined as

$$
F_{s, t}=\int_{-\infty}^{\infty} f\left(t^{\prime}\right) \Psi_{s, t}^{*}\left(t^{\prime}\right) d t^{\prime}
$$

where the asterisk means complex conjugation and $\Psi_{s, t}(t)$ is the wavelet function, which is generated by scaling and shifting a mother wavelet $\Psi(t)$ along the time series. The normalizing factor $C_{\Psi}$ depends on the shape of the wavelet function: 


$$
C_{\Psi}=2 \pi \int_{-\infty}^{\infty} \frac{|\hat{\Psi}(\zeta)|^{2}}{|\zeta|} d \zeta
$$

with $\hat{\Psi}(\zeta)$ being the Fourier transformed mother wavelet.

In the current study, the Morlet function-a plane wave modulated by a Gaussian function-has been chosen as the mother wavelet. The small variance of its Fourier transform makes this function well suited to the analysis of series with oscillatory behavior. It has also the advantage that, because of its sinusoidal shape, it is possible to define an equivalency between $s$ and the equivalent Fourier period of the wavelet, which are directly proportional to each other [see Meyers et al. (1993) for the specific relationship].

\section{b. Multiresolution flux decomposition}

The MRFD (Howell and Mahrt 1997; Vickers and Mahrt 2003) is an alternative approach to evaluate turbulent fluxes and other turbulent parameters. The method reduces the contamination of these fluxes by mesoscale motions, large-scale structures, and other nonturbulent contributions, through a suitable selection of the time scales included in the evaluation of the fluxes. Spectra and cospectra are built from the original time series (usually wind components and potential temperature) using the Haar (Haar 1910), rather than the Fourier, transform. The Haar transform is based on a simple subtraction of windowed, unweighted averages of decreasing length. The MRFD requires two time series of length $2^{N}$ (for instance, vertical wind speed $w$ and potential temperature $\theta$ ) with a sampling time $\Delta T$. The process is performed as follows:

1) First, the covariance of the full time series is computed, yielding the total eddy-covariance flux. We refer to it as cumulative multiresolution flux at the scale $2^{N} \Delta T$ (i.e., $\mathrm{CMRF}_{N}$ ).

2) Each series is split up into two subseries of equal length and the respective averages are removed from them. The covariances of the resulting series yield the CMRF at the scale $2^{N-1} \Delta T$ (i.e., $\mathrm{CMRF}_{N-1}$ ).

3) Each subseries is in turn split up into two parts and the respective averages are removed. The resulting covariances now represent the CMRF at the scale $2^{N-2} \Delta T\left(\mathrm{CMRF}_{N-2}\right)$.

4) The process continues up to the step with two-point subseries, yielding $\mathrm{CMRF}_{1}$.

After each iteration, the transformed time series retain only fluctuations with time scales smaller than the length of the last averaging window applied. Every $\mathrm{CMRF}_{n}$ coefficient $(n=1, \ldots, N)$ may be thought of as the average eddy covariance flux of the whole couple of time series, based on averaging windows of $2^{n}$ points. Therefore, $\mathrm{CMRF}_{n}$ coefficients only include the flux produced by fluctuations with a time scale below $2^{n} \Delta T$. The representation of $\mathrm{CMRF}_{n}$ versus the time scale $2^{n} \Delta T$ is similar to Ogive curves (Desjardins et al. 1989; Friehe et al. 1991), but with a spectral decomposition based on the Haar transform instead of the Fourier transform. In turn, the differences between consecutive coefficients form the multiresolution flux cospectra (MRFC):

$$
\mathrm{MRFC}_{n}=\mathrm{CMRF}_{n}-\mathrm{CMRF}_{n-1} \text {, }
$$

where $n=1, \ldots, N$ and $\mathrm{CMRF}_{0}=0$, since 1-point subseries have no variance or covariance. A plot representing the $\mathrm{MRFC}_{n}$ versus the time scale $\tau=2^{n} \Delta T$ shows the contribution of every spectral range to the total flux. After converting from $n$ to $\tau$, we will refer to these cospectra as $\langle w \theta\rangle_{\tau}$ (or whatever pair of variables had been used). If a spectral gap is identified (i.e., a time scale or range of time scales in which the contribution to the total flux is small or null), it can be set as the upper limit for the integration of the multiresolution cospectra in order to provide a better estimation of the turbulent flux, excluding the large-scale nonturbulent terms.

The procedure described may also be used for spectra evaluation. In this case, it is applied to single time series, and variances are calculated instead of covariances along the different time scales. For instance, the multiresolution decomposition of the velocity components can be used to derive the spectrum of kinetic energy (we avoid the use of the word "turbulent" because the spectrum will be extended to nonturbulent time scales):

$$
\mathrm{KE}_{\tau}=\frac{1}{2}\left[\langle u u\rangle_{\tau}+\langle v v\rangle_{\tau}+\langle w w\rangle_{\tau}\right] .
$$

\section{c. Identification and analysis of structures}

The analysis of time series of atmospheric pressure (or other variables) recorded by an array of sensors has often been used to estimate the spatial characteristics and motion of waves during oscillatory events. These estimations have usually been made through cross correlation (Rees and Mobbs 1988; Einaudi et al. 1989), beamsteering (Denholm-Price and Rees 1999), or other methods of lag analysis (Nappo 2002). All these techniques have the important drawback of a need to determine in advance the ideal analysis window. Since they are applied in a time or in a frequency space, it is sometimes very difficult to build a window that does not contain oscillations other than the structure being analyzed. Terradellas et al. (2001) estimated the wavelength $\lambda$, phase velocity $c$, and direction of propagation dir of structures detected simultaneously in a surface array of 
microbarometers from the phase differences of the wavelet transformed time series. ${ }^{1}$ This method yields a result $(\lambda, c, \operatorname{dir})$ as a function of time and scale and avoids the need for a precise window definition. Nevertheless, it fails to yield a unique value for the wave parameters.

In this paper, we use cross correlation in the wavelet domain, sometimes referred to as wavelet cross correlation. The method, described by Gao and $\mathrm{Li}(1995)$ and $\mathrm{Li}$ and Nozaki (1997), yields a unique solution $(\lambda, c$, dir) for the whole analysis window and therefore requires a preliminary definition of this window, as in ordinary cross correlation. Nevertheless, the definition is performed in a time-scale space where the elimination of spurious oscillations from the perturbation of interest is easier and more precise than in the physical or spectral domains. Given the timescale window $\left(t_{1}: t_{2}, s_{1}: s_{2}\right)$, for any pair of records $(f, g)$, the method finds the time lag $\xi$ that maximizes the following function:

$$
f \circ g(\xi)=\int_{s_{1}}^{s_{2}} \int_{t_{1}}^{t_{2}} F_{s, t}^{*} G_{s, t+\xi} d s d t,
$$

where $F_{s, t}$ and $G_{s, t}$ are the wavelet transforms of $f$ and $g$. The lag represents the time the wave front takes to travel from one sensor to the other. After this time lag has been computed for two different pairs of sensors, the solution of a simple geometric problem yields the values of $c$, dir, and $\lambda$.

In addition to the phase velocity, it is also interesting to evaluate the group velocity $c_{g}$. Using wavelet methods, Meyers et al. (1993) estimated it from the time the maximum of the transform modulus takes to travel between different points. Much more precise is the double transform method described in Terradellas et al. (2001) because it determines the traveling time at any point of the series, not only at the peak. The main problem of the last method is that it requires a relatively good identification of the scale (or frequency) of the perturbation. This identification is not easy because of the intrinsic uncertainty of the wavelet transform.

In this work, group velocities are also evaluated using wavelet cross correlation. The transit times of the energy between the different pairs of sensors is found from the maximization of the convolution of the energy density functions:

\footnotetext{
${ }^{1}$ From surface arrays, only the horizontal propagation of the wave can be studied. Therefore, all references to wave parameters in this study (i.e., phase velocity $c$, wavelength $\lambda$, direction of propagation dir, etc.) refer to the horizontal components of the phase or group velocities.
}

$$
e_{s, t}^{f} \circ e_{s, t}^{g}(\xi)=\frac{1}{C_{\Psi}^{2}} \int_{s_{1}}^{s_{2}} \int_{t_{1}}^{t_{2}}\left|F_{s, t}\right|^{2}\left|G_{s, t+\xi}\right|^{2} \frac{d s d t}{s^{4}} .
$$

\section{d. Evaluation of vertical heat fluxes}

As stated in section 3b, MRFD is used in this paper to analyze how the contribution of the different scales to the total kinetic energy and vertical fluxes changes over the different stages of evolution of the katabatic current. Similar results can be obtained by the application of the wavelet transform to time series of wind components and potential temperature, as in Cuxart et al. (2002) and Terradellas et al. (2005). The vertical kinematic heat flux density per scale unit $H_{s, t}$ can be defined after the generalization of Eq. (1) for two different variables:

$$
H_{s, t}=\frac{2}{C_{\Psi}} \frac{\Theta_{s, t} W_{s, t}^{*}}{s^{2}},
$$

where $W_{s, t}$ and $\Theta_{s, t}$ are, respectively, wavelet transformed vertical wind component and potential temperature. Both methods have similar performance and, when a spectral gap is identified, integrating multiresolution cospectra or cross-wavelet coefficients per unit scale up to a time scale close to the gap, yield substantially improved results when compared to traditional eddy-covariance calculations.

The Morlet wavelet is a natural choice when the object of study consists of perturbations causing smooth variations in the time series (e.g., gravity waves, whose oscillations are indeed very similar in shape to the Morlet wavelet). On the other hand, the footprints left by turbulence in atmospheric time series are far from being smooth. Therefore, the Haar transform used in the MRFD method is more suitable for the study of turbulent signals (Howell and Mahrt 1997). Here, the concept of "time scale" is related to the width of the fluctuations in the time series, as opposed to the periodicity from the wavelet or Fourier transforms, which is primarily influenced by the lag between fluctuations in the time series. Turbulent motions are not periodic events (e.g., Tennekes 1976), which may lead to some interpretation issues when using Fourier or Morlet as a basis for a multiscale decomposition. Howell and Mahrt (1997) compared multiresolution and Fourier-based cospectra from aircraft data and detected a regular shift of the relevant peaks in Fourier cospectra toward larger length scales.

The wavelet transform allows estimation of local spectra and cospectra at every single point of the time series. The temporal resolution of a wavelet transform is evaluated through the variance of their wavelet functions 
$\Psi_{s, t}(t)$, which is proportional to the scale of the wavelet (Mallat 1998). For a well-localized mother wavelet as the Morlet function, this means that the smaller transporting eddies can be resolved almost individually. By contrast, the MRFD provides an ensemble mean of the turbulence along the analyzing window of length $2^{N} \Delta T$ (the temporal resolution common to all time scales), which may be preferable for some applications. For instance, in a stable case where the turbulent heat flux should be downward (negative), part of the turbulent eddies would transport heat upward just by chance, which will produce unexpected positive flux in a fraction of the local wavelet cospectra. In this way, some important average features of the turbulence may be masked by the excessive resolution provided by the wavelet transform. The maxima in spectra and cospectra, as well as the gap separating turbulence from largerscale motions, cannot easily be located in wavelet periodograms: as is often said, "you can't see the wood for the trees." For the reasons set out above, in the following sections the wavelet transform is used whenever the stress of the discussion is on the low-frequency, larger-scale features and the MRFD is used when the behavior of turbulence needs to be explored in detail.

\section{Results}

\section{a. Overview of the night and outbreak of the drainage current}

The synoptic situation of the night of 22-23 June 2006 was dominated by a high pressure area centered northwest from the Azores Islands and covering most of the northern Atlantic midlatitudes. There was a very weak horizontal pressure gradient over the Iberian Peninsula, as may be seen in the surface analysis at 0000 UTC 23 June 2006 made by the High-Resolution LimitedArea Model (HIRLAM) at a $0.5^{\circ}$ horizontal resolution (see Fig. 2).

Under these conditions, a sudden shift in the wind has commonly been observed at the CIBA site (Yagüe et al. 2007). It usually occurs between several tens of minutes and a few hours after the establishment of the stable regime. In any case, during the night of our study, a rapid reorganization of the dynamic and the mass fields was produced soon after sunset (which took place at 1958 UTC). The values recorded at the different levels of the mast (Fig. 3) show a weak northwest wind during the late afternoon, turning north and northeast after sunset, at a rate that points to the presence of an inertial oscillation. Surface radiative cooling favored a temperature inversion of nearly $5^{\circ} \mathrm{C}$ between the surface and the top of the 100-m mast. The pressure records from the three

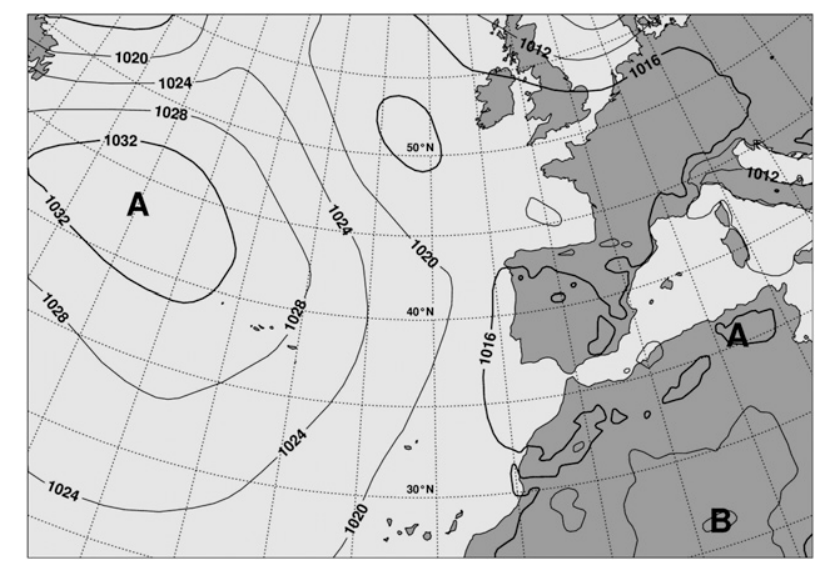

FIG. 2. Sea level pressure analysis at 0000 UTC 23 Jun 2006 made by HIRLAM.

surface microbarometers enable the analysis of the horizontal pressure gradient during this night (Fig. 4). In the evening and early night hours, the strong daytime local pressure gradient pointing southeast quickly evolved to a nearly flat nocturnal pressure field. Similar variations occurred on other days of the campaign (not shown), suggesting that fast local-scale variations are usual on days with a weak synoptic-scale pressure gradient.

The aforementioned wind shift was produced around 2130 UTC, when a sudden intrusion of an eastern current of moderate speed (about $10 \mathrm{~m} \mathrm{~s}^{-1}$ at the highest levels of the mast) occurred. The sudden change in the wind velocity matched a rapid fall in temperature, especially at the highest levels (Fig. 3c). There was a reduction of the thermal inversion and an increase of the specific humidity (Fig. 3d). These changes suggest the outbreak of a katabatic flow. Nevertheless, the absence of steep slopes in the surroundings and a distance of more than $100 \mathrm{~km}$ to the nearest mountains lead us to rule out a pure drainage flow as the cause of the irruption. Previous studies based on different mesoscale models (Bravo et al. 2008; Cuxart 2008; Martínez et al. 2010) have shown that under a weak synoptic-scale forcing, a complex set of drainage flows and nocturnal mesoscale circulations of different scales usually develop, interact, and become organized within the Duero basin. These drainage circulations typically lead to a northeast flow over the Torozos plateau (see Fig. 1 in Martínez et al. 2010), which is consistent with observations at the experimental site during this and similar nights of the campaign. However, complete experimental evidence of these modeled circulations throughout the whole Duero basin is not available: in a stably stratified environment, wind records of ordinary weather stations, with sensors at $10 \mathrm{~m}$ AGL, usually include values that are too weak and too much 

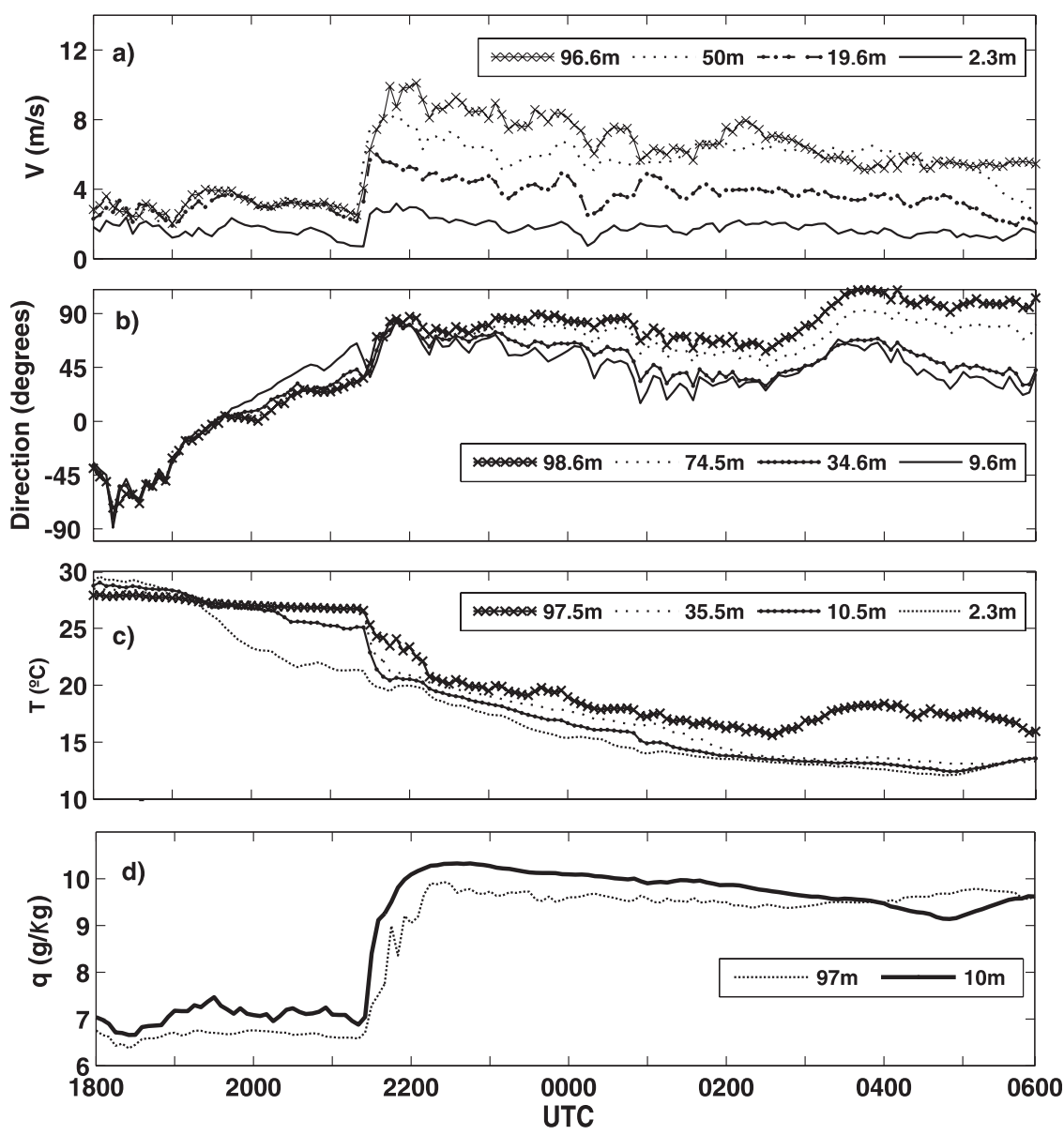

FIG. 3. (a) Wind speed, (b) wind direction, (c) temperature, and (d) specific humidity at different tower levels during the night of 22-23 June 2006.

affected by small-scale topographical or land-use features to be used in mesoscale analysis.

\section{b. Findings from tower microbarometers}

Static atmospheric pressure is not a local flow variable; the atmospheric pressure at a given location depends on the whole overlying atmospheric layer. This is also true for the small pressure fluctuations measured by microbarometers, which can be affected by perturbations far above the measuring point (Monin and Yaglom 1975). When several instruments are available at different heights, the analysis of the pressure differences between levels isolates phenomena occurring in the column bounded by the measuring levels.

The middle and lower time series of Fig. 5a represent the pressure differences between the three measuring levels $\left(\Delta P_{50-100}\right.$ and $\left.\Delta P_{20-50}\right)$. The irruption of the colder air mass is clearly visible in these records: both time series present a pressure rise around 2130 UTC, indicating a sudden fall of the air temperature in these layers (the rise is also present in the upper series, $\left.P_{100}\right)$. The wavelet transforms of the pressure differences are shown in Figs. $5 \mathrm{~b}$ and $5 \mathrm{c}$. The outbreak of the drainage flow produces an increase in the wavelet energy density per time and period unit of $\Delta P_{20-50}$ from 2125 to 2130 UTC (Fig. 5c). Since it is a nonoscillatory event, a wide range of periods from 1 to $20 \mathrm{~min}$ is affected. Although the outbreak of the cold current lasts for a brief time period, it appears enlarged in time by the intrinsic uncertainty of the wavelet transform. A similar signal also appears in the wavelet transform of the pressure records gathered in the surface array (not shown). On the contrary, the signal is scarcely perceptible in the wavelet transform of $\Delta P_{50-100}$ (Fig. 5b) and is not present at all in the wavelet transform of $P_{100}$ (not shown). It means that the drainage flow has an initial depth of slightly more than $50 \mathrm{~m}$. Using surface pressure data and the wavelet cross-correlation technique, the group velocity and direction of the cold current were determined to be about $6.2 \mathrm{~m} \mathrm{~s}^{-1}$ and $350^{\circ}$, respectively. The sudden increase in the meridional 

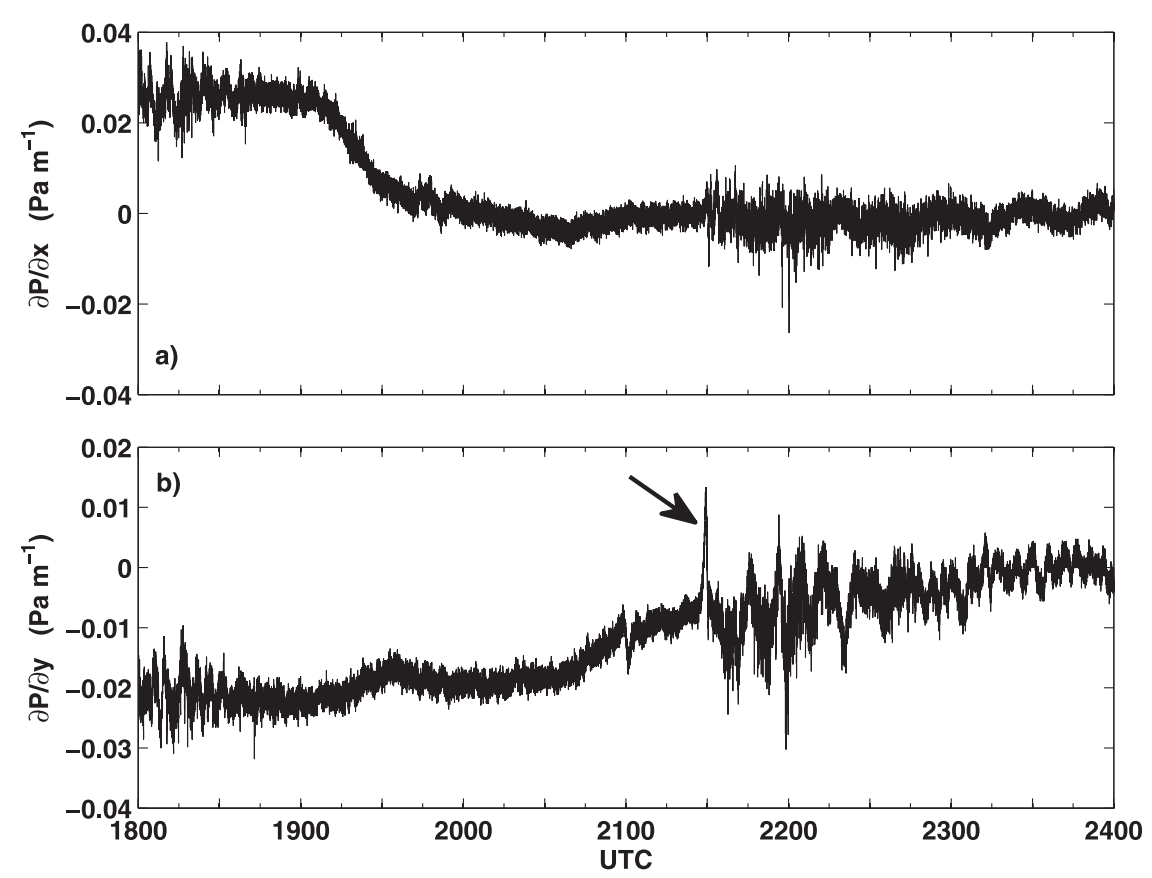

FIG. 4. (a) Zonal and (b) meridional components of the horizontal pressure gradient during the first half of the night of 22-23 June, estimated from the horizontal array of microbarometers. Arrow marks the arrival of the cold current.

component of the pressure gradient (arrow in Fig. 4b) at the time of the irruption of the drainage current fits in with the idea of a northern origin of the cooler air mass.

After the initial outbreak of the drainage current, traces of IGWs appear in the pressure records. They are easily observed in $\Delta P_{50-100}$ and its wavelet transform (Figs. 5a,b), where there is an intense peak, centered around 2200 UTC, with a period of around $9 \mathrm{~min}$. The wavelet transform of these high-resolution pressure records proves to be a valuable source of information when trying to establish a conceptual model of the outbreak of the drainage flow and the subsequent generation of gravity waves. Furthermore, it may help to provide a better interpretation of the evolution of other variables measured at the site. Figure 6 a shows the vertical cross section of the drainage flow reaching the site. It recalls the classic picture of a cold front. The measuring tower is drawn at different time points representing its position relative to the drainage current, and the different graphs below show the time series of vertical wind speed, temperature, and pressure at different levels. The timeline of events can be sketched as follows:

1) At time $A$, the drainage current has not yet arrived at the site. All variables are steady.

2) The cold air mass reaches the tower at time B; it affects levels below 50m AGL in the first place (the temperature falls in one single step at $z=19.6 \mathrm{~m}$ ). The displaced air in these levels is pushed upward (an updraft current is clearly noticeable in the vertical wind speed record at $z=96.6 \mathrm{~m}$ shortly before 2130 UTC; Fig. 6c), producing a first drop in the temperature at $z=96.6 \mathrm{~m}$ due to the arrival of colder air from below. A small downdraft can be seen at $z=19.6 \mathrm{~m}$ (see zoomed region below Fig. 6c), indicating lowlevel divergence at the nose of the microfront.

3) At time $C$, the cold current progressively extends to levels above $z=50 \mathrm{~m}$, causing an increase in $\Delta P_{50-100}$.

4) During times D-F, gravity waves are excited slightly below $z=100 \mathrm{~m}$, at the top of the drainage current, as observed in $\Delta P_{50-100}$. Then, as the interface between the cold current and the warmer air mass above is pushed up and down the top of the tower, periodic temperature oscillations at $z=96.6 \mathrm{~m}$ are registered. These temperature steps are frequently observed in field studies (Einaudi and Finnigan 1993; Chimonas 1999). First, short pulses of negative temperature anomalies appear, meaning that the main oscillations are produced below that level. Then, as the thickness of the cold current grows, the warmcold boundary gets closer to the measurement level, and the cold temperature anomalies take up longer time intervals. Eventually, as the separating layer is displaced well above, these oscillations vanish at around 2215 UTC.

Surface microbarometers also registered a lowfrequency periodic disturbance similar to that shown in 

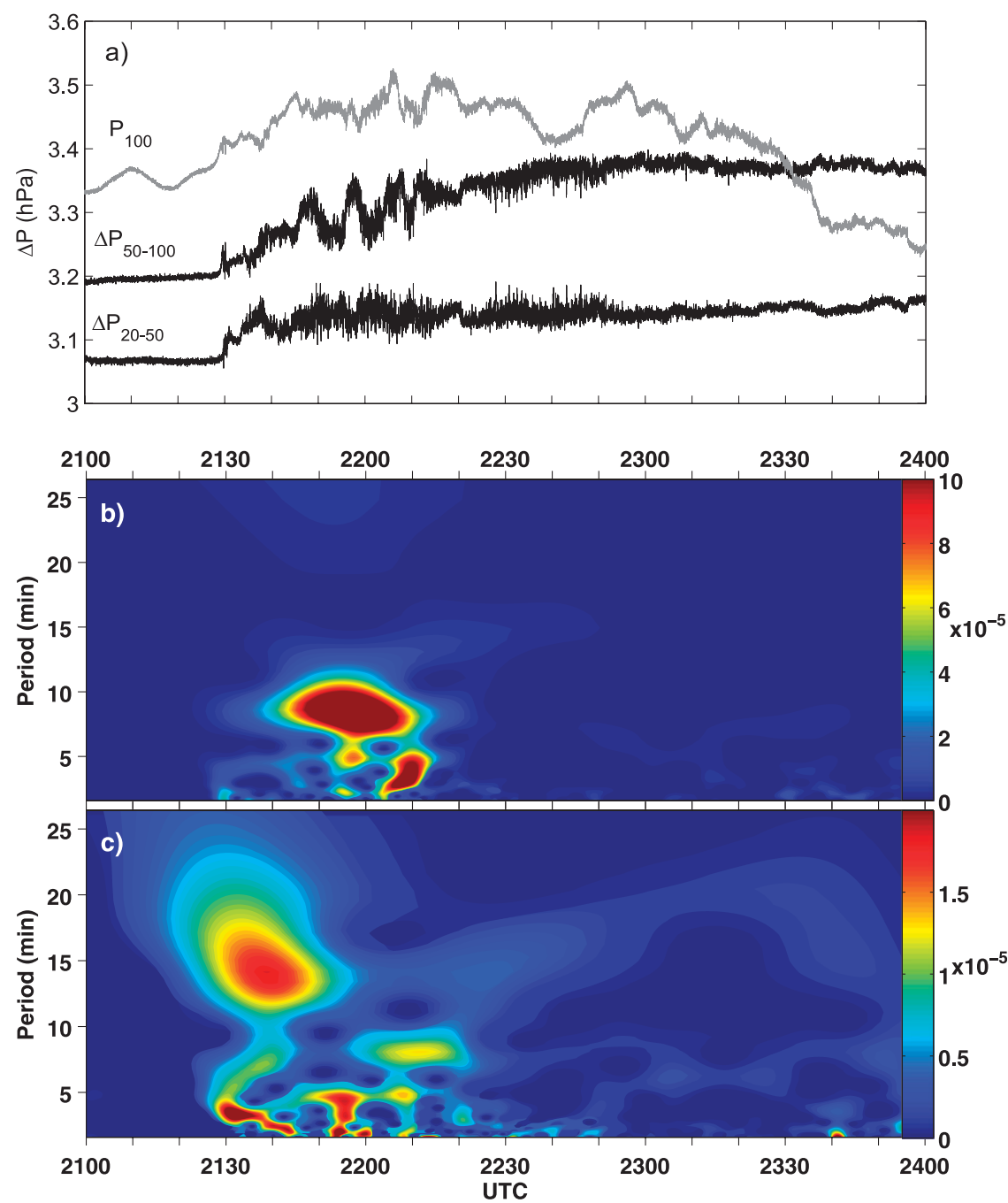

FIG. 5. Values of (a) $P_{100}(-905.5 \mathrm{hPa}), \Delta P_{50-100}(-1.6 \mathrm{hPa})$ and $\Delta P_{20-50}$ on $22 \mathrm{Jun} 2006$. The wavelet transforms of the (b) middle and (c) lower time series, respectively.

Fig. 6b. Results from wavelet cross correlation show that the wave, with a period around $9.2 \mathrm{~min}$, propagated roughly from the north $\left(20^{\circ}\right)$ with a phase velocity of $6.5 \mathrm{~m} \mathrm{~s}^{-1}$ and a wavelength of nearly $3500 \mathrm{~m}$. A rough estimation of the Brunt-Väisälä frequency from the temperature profile following the cold air mass predicts oscillations with a period of around $3 \mathrm{~min}$ at least. Regardless of the roughness of the estimation, the observed period is also compatible with the minimum for an isothermal atmosphere (5 min; Nappo 2002).

After 2230 UTC, $\Delta P_{50-100}$ and $\Delta P_{20-50}$ are nearly constant, revealing the homogeneous and nearly stationary structure of the temperature inversion below $100 \mathrm{~m}$ (the rate of radiative cooling is approximately the same for all tower levels from 2230 to 0230 UTC; Fig. 3c). The drainage current had flooded low levels and its top was well above $100 \mathrm{~m}$. The pressure disturbances observed earlier in $\Delta P_{50-100}$ have now shifted to higher levels and can be observed in $P_{100}$, embedded in a slow mesoscale pressure trend (Fig. 7a). Sodar data reveal that the drainage current had formed a low-level jet (LLJ) with a peak at around $160 \mathrm{~m}$, and that the cold air of the drainage current had mixed with the warmer air above (not shown); the initial warm-cold interphase had thickened and formed a smooth transitional inversion layer that extended up to $180-200 \mathrm{~m}$. As a result, waves were not trapped vertically in a thin layer around $100 \mathrm{~m}$ and were able to propagate more freely up and down within the drainage current, sensing and reacting to the different local conditions as they move, leading to a less monochromatic behavior. The wavelet transform of $P_{100}$ reveals the existence of intermittent oscillations with 

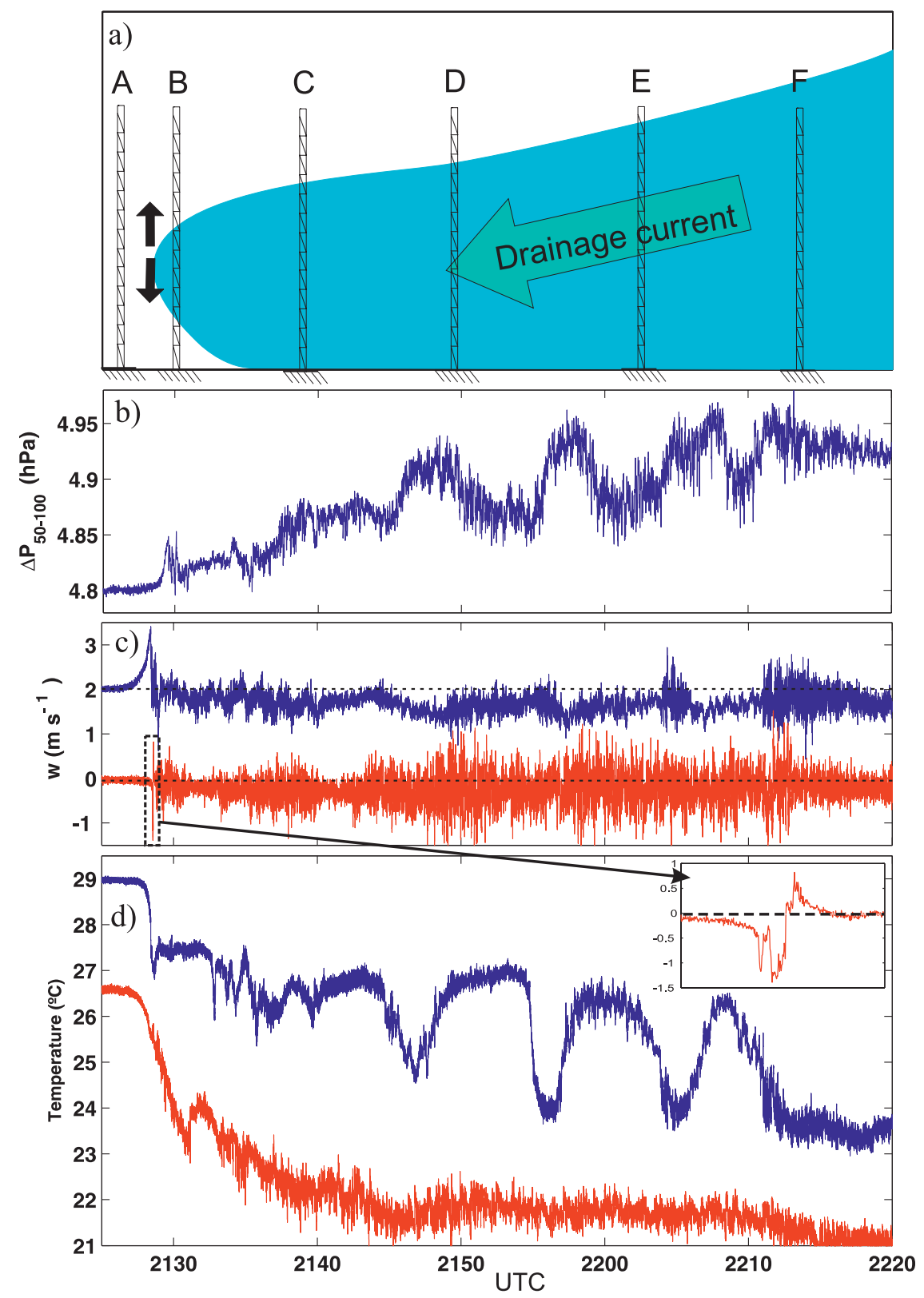

FIG. 6. (a) Schematic view of the shape of the drainage current and location of the measuring tower relative to it at six different instants, (b) $\Delta P_{50-100}$, (c) vertical wind speed at $z=19.6$ (red) and $96.6 \mathrm{~m}$ (blue) $\left(+2 \mathrm{~m} \mathrm{~s}^{-1}\right)$, and (d) virtual temperature measured by the sonic anemometers at $z=19.6$ (red) and $96.6 \mathrm{~m}$ (blue) $\left(+2^{\circ} \mathrm{C}\right)$.

periods between 15 and 20 min (Fig. 7b). Cross-correlation analysis of some of these disturbances observed from the surface array results in wave parameters similar to those of the wave analyzed at 2200 UTC (see Table 2 for a summary of the events characterized using cross correlation). Sometimes the amplitude of the pressure fluctuations at $z=100 \mathrm{~m}$ decreases during a few minutes and new pressure fluctuations appear at lower layers (for instance, at around $0140-0220$ UTC at $\Delta P_{50-100}$, or at around 0400 UTC at $\Delta P_{50-100}$ and $\Delta P_{20-50}$; Fig. 7a). It suggests that the gravity waves suffered transient incursions to levels below $z=100 \mathrm{~m}$. Their wave parameters are in accordance with the aforementioned idea (see last row in Table 2): dir is similar to that of the "mother" waves but, since the waves were accessing atmospheric layers with stronger stratification, the period is lower, as can be explained by wave theory (e.g., Stull 1988; Nappo 2002). 


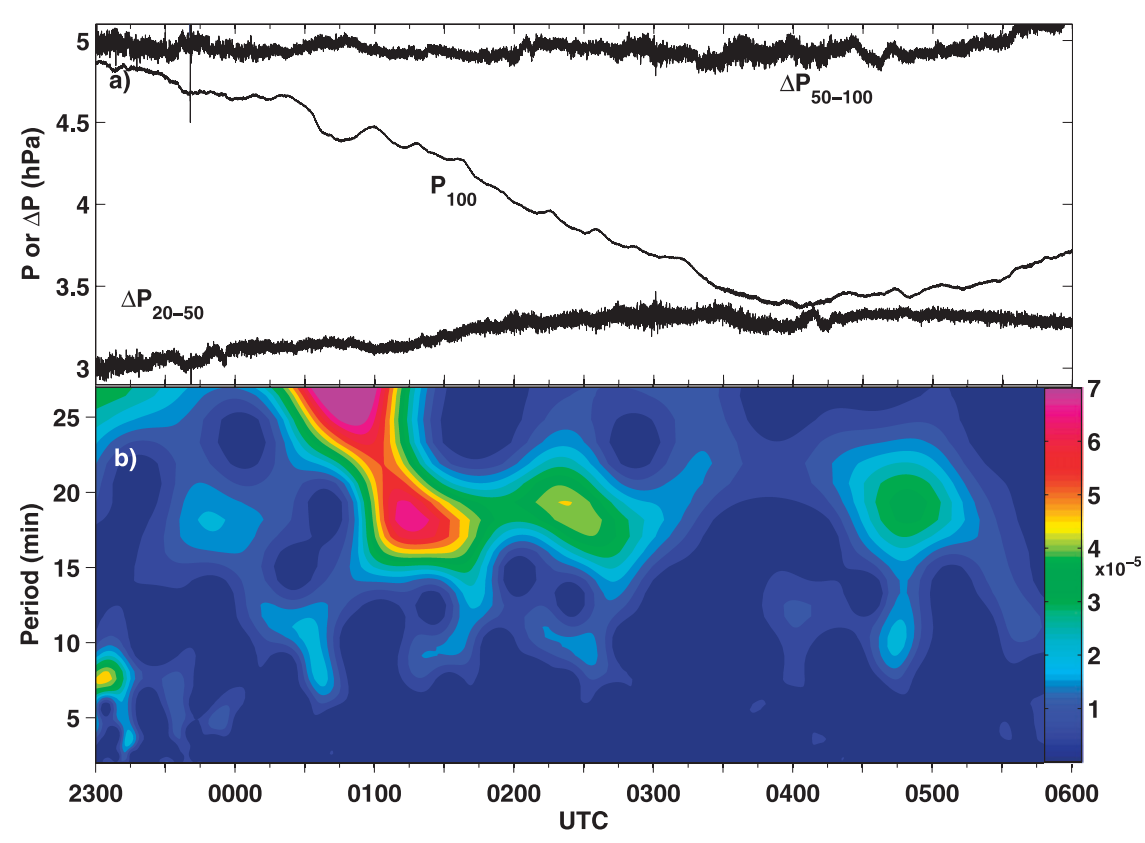

FIG. 7. (a) Values of $\Delta P_{50-100}(-1.6 \mathrm{hPa}), P_{100}(-904 \mathrm{hPa})$, and $\Delta P_{20-50}$;

(b) wavelet energy density of $P_{100}\left(\mathrm{hPa}^{2} \mathrm{~s}^{-1}\right)$.

\section{c. Turbulent and low-frequency fluxes}

In this section, classic micrometeorological parameters such as heat fluxes or kinetic energy are analyzed by means of multiresolution and wavelet transform. MRFD of vertical heat flux $\langle w \theta\rangle_{\tau}$ and kinetic energy $\mathrm{KE}_{\tau}$ have been evaluated for the whole night, using 13.6-min subseries ( $820 \mathrm{~s}, 2^{14}$ data points) recorded by the sonic anemometers. The subseries have been constructed with a 60 -s overlap in order to achieve better time resolution. A planar-fit (long term) rotation (Wilczac et al. 2001) is performed before applying the multiresolution algorithm to define the vertical axis $z$ and calculate the corrected vertical wind component $w$. Results for $z=19.6 \mathrm{~m}$ and $z=96.6 \mathrm{~m}$ are shown in Figs. 8 and 9 using contour plots. Each vertical slice in these figures can be thought of as the local multiresolution spectrum (for the kinetic energy) or cospectrum (for the heat flux).

We begin by studying turbulence at low levels (Fig. 8). The surface layer usually presents the strongest wind shear and well-defined spectra and cospectra. Different features of the evolution of the spectrum of turbulence are revealed at $z=19.6 \mathrm{~m}$. First, a period of quiescent turbulence preceded the cold air mass, which reached the site about 2130 UTC. Although there was a temperature inversion close to the surface below $z=10.5 \mathrm{~m}$ due to radiative cooling, the lapse rate and the wind shear around $z=19.6 \mathrm{~m}$ and above were null or very small (this can be seen in Figs. 3a and 3c). Turbulence was probably restricted to a shallow layer over the ground. After the outbreak of the cold air mass, strong wind shear developed from the surface to at least $z=96.6 \mathrm{~m}$ and, in spite of the abrupt cooling, the temperature difference between 2.3 and $97.5 \mathrm{~m}$ was more homogeneously distributed. Then, a downward turbulent heat flux and the typical turbulence spectrum of stable atmospheres with weak or moderate stratification (Vickers and Mahrt 2003; Viana et al. 2008, 2009) quickly developed. The maximum contributions are found around $10 \mathrm{~s}$ (Figs. 8a,b; around 2130-2200 UTC), revealing the mean time scale of the turbulent eddies. This turbulent heat flux remains during the rest of the night, although it is more

TABLE 2. Events analyzed with wavelet cross correlation and their main parameters.

\begin{tabular}{|c|c|c|c|c|}
\hline Type of event & Time (UTC) & Period (min) & $c$ and/or $c_{g}(\operatorname{dir})$ & $\lambda$ (if applicable) \\
\hline Katabatic irruption & 2130 & $2-10$ & $c_{g}=6.3 \mathrm{~m} \mathrm{~s}^{-1}\left(\operatorname{dir}=351^{\circ}\right)$ & - \\
\hline $\begin{array}{l}\text { Gravity wave along the } \\
\text { cold-warm interphase }\end{array}$ & $2145-2215$ & 9.2 & $\begin{aligned} c & =6.2 \mathrm{~m} \mathrm{~s}^{-1}\left(\operatorname{dir}=20^{\circ}\right) \\
c_{g} & =6.5 \mathrm{~m} \mathrm{~s}^{-1}\left(\operatorname{dir}=351^{\circ}\right)\end{aligned}$ & $3400 \mathrm{~m}$ \\
\hline Gravity wave above $100 \mathrm{~m}$ & 0050-0140 & 18 & $c=7.2 \mathrm{~m} \mathrm{~s}^{-1}\left(\operatorname{dir}=2^{\circ}\right)$ & $7800 \mathrm{~m}$ \\
\hline Gravity wave between 50 and $100 \mathrm{~m}$ & 0140-0220 & 10 & $c=8.3 \mathrm{~m} \mathrm{~s}^{-1}\left(\operatorname{dir}=14^{\circ}\right)$ & $5000 \mathrm{~m}$ \\
\hline
\end{tabular}



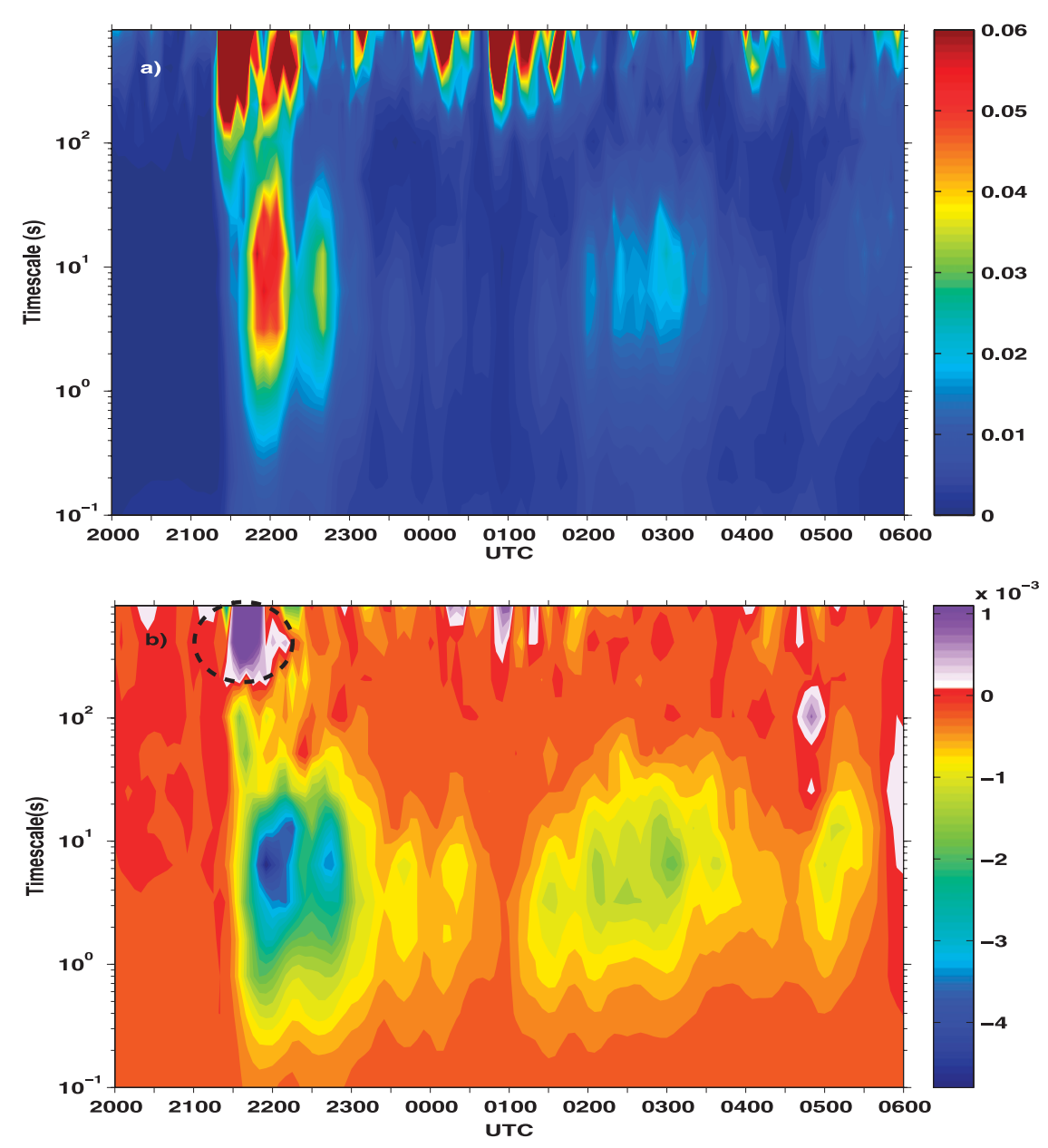

FIG. 8. Multiresolution decomposition of (a) kinetic energy $\left(\mathrm{m}^{2} \mathrm{~s}^{-2}\right)$ and (b) vertical heat flux $\left(\mathrm{K} \mathrm{m} \mathrm{s}^{-1}\right.$ ) evaluated at $z=19.6 \mathrm{~m}$ from 2000 to 0600 UTC.

intense right after the irruption of the cold current, and it is temporarily weakened from 2330 to 0100 UTC. During most of the night, the gap separating turbulence from mesoscale motions is located between 50 and $200 \mathrm{~s}$ (not shown). This result is similar to that obtained in Viana et al. (2009) on a weakly stable night with similar values of wind shear but no thermal inversion.

Unexpected positive (countergradient) heat fluxes are found for a few minutes around 2125 UTC at large time scales, between 200 and $800 \mathrm{~s}$ approximately (see circled region in Fig. 8b). These fluxes are due to the combined, though physically unrelated, action of (i) the rapid drop of nearly $5^{\circ} \mathrm{C}$ in temperature at $z=19.6 \mathrm{~m}$, occurring from 2128 to 2140 UTC, and (ii) the downward motion established within the drainage air mass at $z=19.6 \mathrm{~m}$ (vertical wind speed values at that height in Fig. $6 \mathrm{c}$ are mainly negative after 2130 UTC). Multiresolution fluxes resulting from temperature and vertical wind speed time series covering these events connect negative perturbations of $w$ and $T$, resulting in a transient upward heat flux, which (unlike the turbulent transfer) is due not to a thermal stratification but to a cold horizontal advection.

The picture at $96.6 \mathrm{~m} \mathrm{AGL}$ is completely different. Figure 9 shows $\mathrm{KE}_{\tau}$ and $\langle w \theta\rangle_{\tau}$ at that level. Turbulence excited after the arrival of the cold current is much weaker than at $z=19.6 \mathrm{~m}$, and it lasts for a shorter time period. A regular, turbulent cospectrum of downward heat flux is only noticeable for a few minutes around 2200 UTC (Fig. 9b), but the maximum revealing the mean turbulent eddies is spread along time scales between 1 and $15 \mathrm{~s}$. The shape of the turbulent heat cospectrum is platykurtic during this period, or nearly flat during the rest of the night. This is due to the higher homogeneity of wind and temperature at this level (i.e., small vertical gradients inhibit turbulent motions) and to the inability of the sonic anemometers to correctly resolve the smallest turbulent eddies, as is explained in Viana et al. (2009). The spectral gap is also not well 


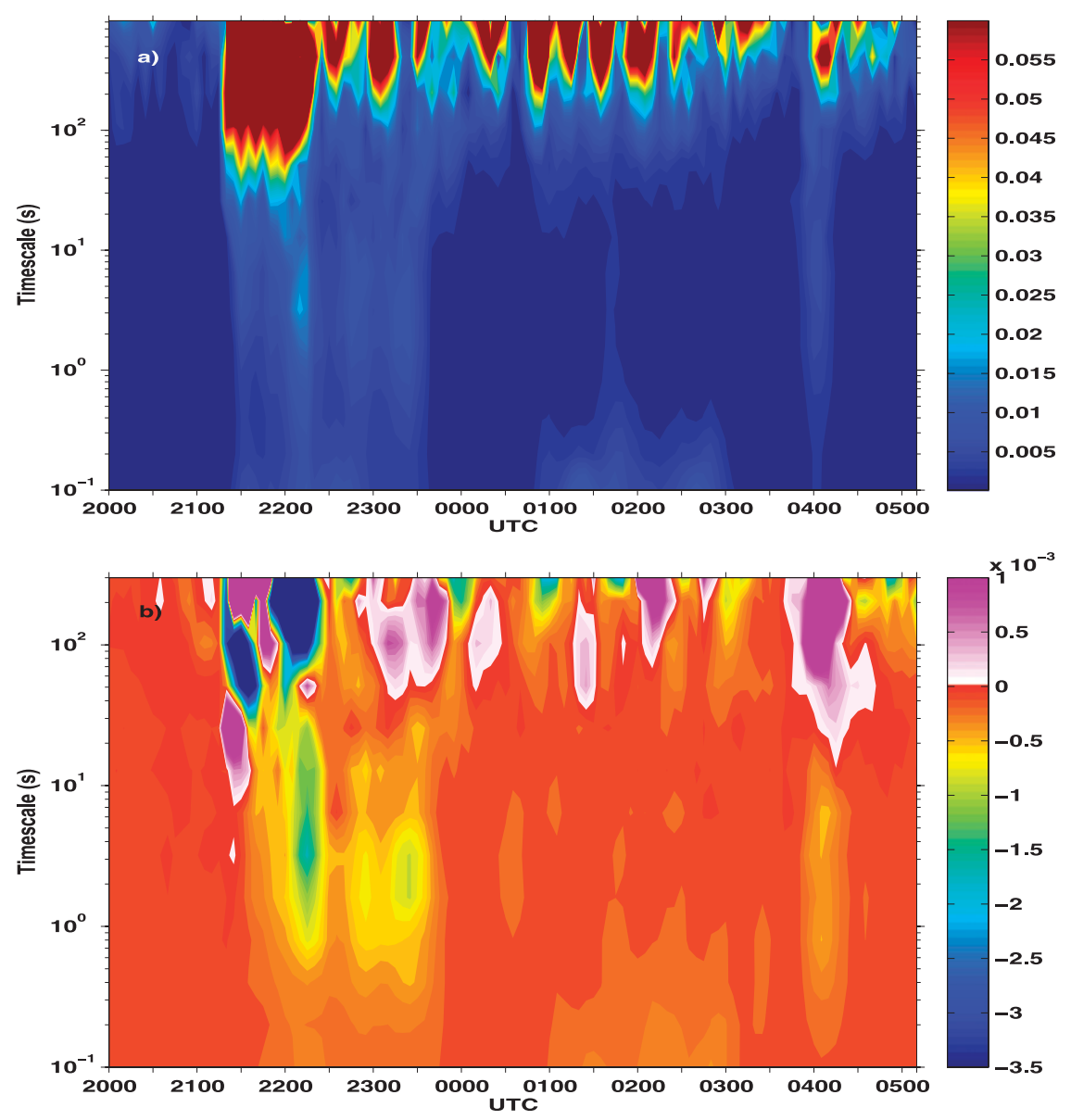

FIG. 9. As in Fig. 8, but evaluated at $z=96.6 \mathrm{~m}$ from 2000 to 0510 UTC.

defined because of the overlapping of strong contributions of mesoscale or submesoscale motions (some falling out of the range of values used in the color bar), with time scales larger than $100 \mathrm{~s}$ (Figs. 9a,b, from 2130 UTC onward, but especially until 2230 UTC). These nonturbulent motions were not affected by the inhibition produced by the small vertical gradients of wind and temperature.

Among these motions were the gravity waves present at this level, which are better described in terms of wavelet analysis than using multiresolution, as explained earlier, in section $3 \mathrm{~d}$. Therefore, time scales from 5 to $20 \mathrm{~min}$ have been reanalyzed using wavelet transform to compute vertical fluxes. Results from 2100 to 2300 and from 0030 to 0300 UTC are studied (Fig. 10). The most remarkable feature is the dipole structure of positivenegative heat flux present from 2145 to 2215 UTC (Fig. 10a). Different signs suggest that the structure is related to the IGW described in the previous section. First, its time and period match those of the waves. In addition, upward heat flux turns downward at the precise time that the cold-warm interphase, where the IGW was trapped, surpasses the measuring level $(z=96.6 \mathrm{~m})$. As is widely known, linear wave theory predicts that the total vertical heat flux induced by a gravity wave should be zero, since the oscillations of vertical velocity and potential temperature should be $90^{\circ}$ out of phase. However, most gravity waves observed in field experiments do not show regular, monochromatic behavior (e.g., Chimonas 1999; Nappo 2002). Furthermore, several authors report nonzero vertical heat fluxes at the scale of the wave (Finnigan and Einaudi 1981; Finnigan 1988). Viana et al. (2009) studied from multiresolution decomposition the scale interaction between turbulence and a ducted gravity wave episode of high amplitude and mesoscale extension. They showed the overlapping of both types of motions along similar time scales, as well as a waverelated heat flux changing from positive to negative values every few minutes in an irregular way. Results in the present case suggest the existence of an upward flux above the main level of the oscillation and a downward flux below it. This vertical heat flux divergence 

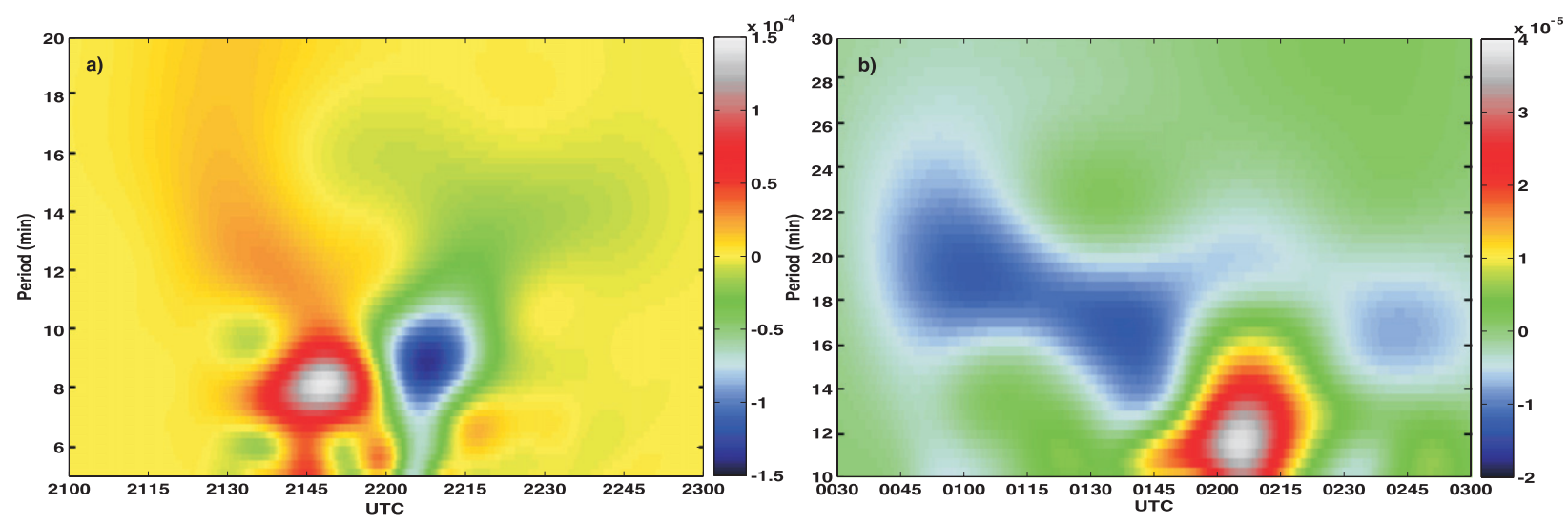

FIG. 10. Vertical kinematic heat flux density per scale unit $\left(\mathrm{K} \mathrm{m} \mathrm{s}^{-2}\right)$ at large time scales evaluated at $z=96.6 \mathrm{~m}$ at different moments of the night showing wave activity.

around a gravity wave may be not a particular but a general result. Figure 10b shows a sort of tripole of negative-positive-negative heat flux at $z=96.6 \mathrm{~m}$ around 0200 UTC, when the analysis of pressure differences suggests a fast, transient incursion of a gravity wave below $z=100 \mathrm{~m}$ (Fig. 7a).

\section{Summary and conclusions}

A single night from SABLES 2006 field campaign, which may be considered as "prototypical" of the nocturnal evolution of the planetary boundary layer at the CIBA site when the synoptic forcing is weak, has been studied. The focus was centered on the effects of a drainage current regularly established at the site, with special emphasis on the generation of gravity waves at its top. The analysis of the local surface pressure gradient, as well as pressure differences between levels, helps to establish a conceptual model for the spreading of the cold current along the plateau, improving the interpretation of other atmospheric variables, such as the evolution of the heat fluxes. The drainage current in many senses resembles a classic cold front. Its irruption causes horizontal mass convergence and, therefore, induces an upward motion that is a source of gravity waves: in the case analyzed, these are shown to propagate first along a thin atmospheric layer separating the cold current from the pre-existing warmer air, and then to lose their nearmonochromatic character and move along a broader layer as both air masses mix together.

The main parameters of the IGW $\left(c, c_{g}, \lambda\right.$, dir, etc. $)$ as well as the velocity and direction of the arriving cold current were determined through wavelet cross correlation, a methodology that has proved to be easier to apply and less demanding than previous methods. Both the cold current and the induced waves propagate southward with similar phase and group speeds, which proves the link between both processes.

By means of both multiresolution and wavelet analysis, the vertical heat flux and the kinetic energy have been studied from sonic anemometer data both at the time scales of the turbulence and the waves. An increase in turbulent activity at $z=19.6 \mathrm{~m}$ and $z=96.6 \mathrm{~m}$ is produced at the outbreak of the cold current: at some periods, this turbulent activity overlaps with a largerscale component produced by the mesoscale contribution, mainly the irruption of the cold current and the formation and vertical displacement of the gravity wave. Of particular interest is a heat flux divergence produced by the wave moving vertically, which could explain the countergradient fluxes sometimes found in the stable boundary layer, associated with the presence of IGWs but without a clear physical interpretation in the literature (Nai-Ping et al. 1983; Yagüe and Redondo 1995). It seems to be a typical footprint of gravity waves observed at the site; however, further studies are needed to clarify the importance of these flux components, which may become a key factor to force the vertical profile of wind and temperature when other factors (i.e., turbulence) are weak.

Acknowledgments. The authors wish to thank Dr. Javier Peláez and Prof. Casanova, staff member and Director of the CIBA, for their technical support and help through the SABLES 2006 campaign. This research has been funded by the Spanish Ministry of Science and Innovation (Projects CGL2004-03109, CGL 2006-12474C03-03, and CGL2009-12797-C03-03). The GR58/08 program (supported by BSCH and UCM) has also partially financed this work through the Research Group "Micrometeorology and Climate Variability" (910437). We are also grateful to the two anonymous reviewers and the editor for their useful comments. 


\section{REFERENCES}

Acevedo, O. C., and L. Mahrt, 2010: Systematical vertical variation of mesoscale fluxes in the nocturnal boundary layer. Bound.-Layer Meteor., 135, 19-30.

Banta, R. M., and P. T. Gannon Sr., 1995: Influence of soil moisture on simulations of katabatic flow. Theor. Appl. Climatol., 52, 85-94.

— L. Mahrt, D. Vickers, J. Sun, B. B. Balsley, Y. L. Pichugina, and E. J. Williams, 2007: The very stable boundary layer on nights with weak low-level jets. J. Atmos. Sci., 64, 30683090.

Barry, R. G., 1992: Mountain Weather and Climate. 2nd ed. Routledge, $402 \mathrm{pp}$.

Bastin, S., and P. Drobinski, 2005: Temperature and wind velocity oscillations along a gentle slope during sea-breeze events. Bound.-Layer Meteor., 114, 573-594.

Belušić, D., and I. Güttler, 2010: Can mesoscale models reproduce meandering motions? Quart. J. Roy. Meteor. Soc., 136, 553-565.

Beres, J. H., 2004: Gravity wave generation by a three-dimensional thermal forcing. J. Atmos. Sci., 61, 1805-1815.

Bossuet, C. M., M. Déqué, and D. Cariolle, 1998: Impact of a simple parameterization of convective gravity-wave drag in a stratosphere-troposphere general circulation model and its sensitivity to vertical resolution. Ann. Geophys., 16, 238-249.

Bravo, M., A. Mira, M. R. Soler, and J. Cuxart, 2008: Intercomparison and evaluation of MM5 and Méso-NH mesoscale models in the stable boundary layer. Bound.-Layer Meteor., 128, 77-101.

Cano, D., and E. Terradellas, 2008: A conceptual model of mountain breeze in Madrid. Short-Range Forecasting Methods of Fog, Visibility, and Low Clouds, COST Action 722 Final Rep., European Cooperation in Science and Technology (COST) Office, 63-75. [Available online at http://137.248.191.94/index. php?id=207.]

Chemel, Ch., C. Staquet, and M. Tavernier, 2006: Internal gravity waves generated by katabatic flows in a valley and induced mixing. Extended Abstracts, 12th. Conf. on Mountain Meteorology, Santa Fe, NM, Amer. Meteor. Soc., 5.5. [Available online at http://ams.confex.com/ams/SantaFe2006/techprogram/ paper_114720.htm.]

Chimonas, G., 1999: Steps, waves and turbulence in the stably stratified planetary boundary layer. Bound.-Layer Meteor., 90, 397-421.

Chun, H.-Y., and J.-J. Baik, 1998: Momentum flux by thermally induced internal gravity waves and its approximation for largescale models. J. Atmos. Sci., 55, 3299-3310.

_- M.-D. Song, J.-W. Kim, and J.-J. Baik, 2001: Effects of gravity wave drag induced by cumulus convection on the atmospheric general circulation. J. Atmos. Sci., 58, 302-319.

Conangla, L., J. Cuxart, and M. R. Soler, 2008: Characterisation of the nocturnal boundary layer at a site in northern Spain. Bound.-Layer Meteor., 128, 255-276.

Cuxart, J., 2008: Nocturnal basin low-level jets: An integrated study. Acta Geophys., 56, 100-113.

— Experiment in Spain (SABLES 98): A report. Bound.-Layer Meteor., 96, 337-370.

— G. Morales, E. Terradellas, and C. Yagüe, 2002: Study of coherent structures and estimation of the pressure transport terms for the nocturnal stable boundary layer. Bound.-Layer Meteor., 105, 305-328.
— M. A. Jiménez, and D. Martínez, 2007: Nocturnal meso-beta basin and katabatic flows on a midlatitude island. Mon. Wea. Rev., 135, 918-932.

Daubechies, I., 1992: Ten Lectures on Wavelets. CBMS Lecture Notes Series, Vol. 61, SIAM, 357 pp.

Denholm-Price, J. C. W., and J. M. Rees, 1999: Detecting waves using an array of sensors. Mon. Wea. Rev., 127, 57-69.

Desjardins, R. L., J. I. MacPherson, P. H. Schuepp, and F. Karanja, 1989: An evaluation of aircraft flux measurements of $\mathrm{CO}_{2}$, water vapor and sensible heat. Bound.-Layer Meteor., 47, $55-69$.

Doran, J. C., 1993: An overview of the ASCOT program. Proc. Topical Meeting on Environmental Transport and Dosimetry, Charleston, SC, Amer. Nuclear Soc., 75-88.

_ J. J. Fast, and J. Horel, 2002: The VTMX 2000 campaign. Bull. Amer. Meteor. Soc., 83, 537-551.

Einaudi, F., and J. J. Finnigan, 1993: Wave-turbulence dynamics in the stably stratified boundary layer. J. Atmos. Sci., 50, 18411864.

— A. A. Bedard Jr., and J. J. Finnigan, 1989: A climatology of gravity waves and other coherent disturbances at the Boulder Atmospheric Observatory during March-April 1984. J. Atmos. Sci., 46, 303-329.

Ellison, T. H., and J. S. Turner, 1959: Turbulent entrainment in stratified flows. J. Fluid Mech., 6, 423-448.

Farge, M., 1992: Wavelet transforms and their applications to turbulence. Annu. Rev. Fluid Mech., 24, 395-458.

Finnigan, J. J., 1988: Kinetic energy transfer between internal gravity waves and turbulence. J. Atmos. Sci., 45, 486-505.

_ gravity wave and the planetary boundary layer. Part II: Effect of the wave on the turbulence structure. Quart. J. Roy. Meteor. Soc., 107, 807-832.

,-- , and D. Fua, 1984: The interaction between an internal gravity wave and turbulence in the stably stratified nocturnal boundary layer. J. Atmos. Sci., 41, 2409-2436.

Fournet, M. J., 1840: Des brises de jour et de nuit autour des montagnes (Daytime and nighttime winds around mountains). Ann. Chim. Phys., 74, 337-401.

Friehe, C. A., and Coauthors, 1991: Air-sea fluxes and surface layer turbulence around a sea surface temperature front. J. Geophys. Res., 96, 8593-8609.

Fritts, D. C., 1982: Shear excitation of atmospheric gravity waves. J. Atmos. Sci., 39, 1936-1952.

_ gravity waves. Part II: Frontal, convective, and jet stream excitation. J. Atmos. Sci., 49, 111-127.

Gall, R. L., R. T. Williams, and T. L. Clark, 1988: Gravity waves generated during frontogenesis. J. Atmos. Sci., 45, 2204-2219.

Gao, W., and B.-L. Li, 1995: Wavelet analysis of atmospheric turbulence structures: What can we gain from this new technique? Preprints, 11th Symp. on Boundary Layers and Turbulence, Charlotte, NC, Amer. Meteor. Soc., 27-31.

Gregory, D. G., J. Shutts, and J. T. Mitchell, 1998: A new gravitywave-drag scheme incorporating anisotropic orography and low-level wave breaking: Impact upon the climate of the UK Meteorological Office Unified Model. Quart. J. Roy. Meteor. Soc., 124, 463-493.

Gryning, S.-E., L. Mahrt, and S. Larsen, 1985: Oscillating nocturnal slope flow in a coastal valley. Tellus, 37A, 196-203.

Haar, A., 1910: Zur Theorie der orthogonalen Funktionensysteme (On the theory of orthogonal function systems). Math. Ann., 69, 331-371. 
Helmis, C. G., and K. H. Papadopoulos, 1996: Some aspects of the variation with time of katabatic flow over simple slope. Quart. J. Roy. Meteor. Soc., 122, 595-610.

Hertzog, A., G. Boccara, R. A. Vincent, F. Vial, and P. Cocquerez, 2008: Estimation of gravity wave momentum flux and phase speeds from quasi-Lagrangian stratospheric balloon flights. Part II: Results from the Vorcore campaign in Antarctica. J. Atmos. Sci., 65, 3056-3070.

Howell, J. F., and L. Mahrt, 1997: Multiresolution flux decomposition. Bound.-Layer Meteor., 83, 117-137.

Kershaw, R., 1995: Parametrization of momentum transport by convectively generated gravity waves. Quart. J. Roy. Meteor. Soc., 121, 1023-1040.

Lalas, D. P., and F. Einaudi, 1976: On characteristics of gravity waves generated by atmospheric shear layers. J. Atmos. Sci., 33, 1248-1259.

Larsen, M., W. Swartz, and R. Woodman, 1982: Gravity-wave generation by thunderstorms observed with a vertically pointing 430-MHz radar. Geophys. Res. Lett., 9, 571-574.

Li, J., and H. Nozaki, 1997: Application of wavelet cross-correlation analysis to a plane turbulent jet. JSME Int. J., 40B, 58-66.

Maguire, A. J., J. M. Rees, and S. H. Derbyshire, 2006: Stable atmospheric boundary layer over a uniform slope: Some theoretical concepts. Bound.-Layer Meteor., 120, 219-227.

Mahrt, L., 2007: Weak-wind mesoscale meandering in the nocturnal boundary layer. Environ. Fluid Mech., 7, 331-347.

_ 2010: Variability and maintenance of turbulence in the very stable boundary layer. Bound.-Layer Meteor., 135, 1-18.

Mallat, S., 1998: A Wavelet Tour of Signal Processing. Academic Press, $620 \mathrm{pp}$.

Martínez, D., and J. Cuxart, 2009: Assessment of the hydraulic slope flow approach using a mesoscale model. Acta Geophys., 57, 882-903.

— M. A. Jiménez, J. Cuxart, and L. Mahrt, 2010: Heterogeneous nocturnal cooling in a large basin under very stable conditions. Bound.-Layer Meteor., 137, 97-113.

Mastrantonio, G., F. Einaudi, D. Fua, and D. P. Lalas, 1976: Generation of gravity waves by jet streams in the atmosphere. J. Atmos. Sci., 33, 1730-1738.

McFarlane, N. A., 1987: The effect of orographically excited gravity wave drag on the general circulation of the lower stratosphere and troposphere. J. Atmos. Sci., 44, 1775-1800.

McNider, R. T., 1982: A note on velocity fluctuations in drainage flows. J. Atmos. Sci., 39, 1658-1660.

Meyers, S. D., B. G. Kelly, and J. J. O'Brien, 1993: An introduction to wavelet analysis in oceanography and meteorology: With application to the dispersion of Yanai waves. Mon. Wea. Rev., 121, 2858-2866.

Monin, A. S., and A. M. Yaglom, 1975: Statistical Fluid Mechanics. Vol. 2. MIT Press, 874 pp.

Nai-Ping, L., W. D. Neff, and J. C. Kaimal, 1983: Wave and turbulence structure in a disturbed nocturnal inversion. Bound.Layer Meteor., 26, 141-155.

Nappo, C. J., 2002: An Introduction to Atmospheric Gravity Waves. Academic Press, 276 pp.

- D. R. Miller, and A. L. Hiscox, 2008: Wave-modified flux and plume dispersion in the stable boundary layer. Bound.-Layer Meteor., 129, 211-223.

Parish, T. R., 1984: A numerical study of strong katabatic winds over Antarctica. Mon. Wea. Rev., 112, 545-554.

Patterson, M. D., J. E. Simpson, S. B. Dalziel, and G. J. F. van Heijst, 2006: Vortical motion in the head of an axisymmetric gravity current. Phys. Fluids, 18, 046601, doi:10.1063/1.2174717.
Poulos, G. S., J. E. Bossert, T. B. McKee, and R. A. Pielke, 2000: The interaction of katabatic flow and mountain waves. Part I: Observations and idealized simulations. J. Atmos. Sci., 57, 1919-1936.

,,--- , and 2007: The interaction of katabatic flow and mountain waves. Part II: Case study analysis and conceptual model. J. Atmos. Sci., 64, 1857-1879.

Ralph, F. M., P. J. Neiman, and T. L. Keller, 1999: Deep tropospheric gravity waves created by leeside cold fronts. J. Atmos. Sci., 56, 2986-3009.

Rees, J. M., and S. D. Mobbs, 1988: Studies of internal gravity waves at Halley Base, Antarctica, using wind observations. Quart. J. Roy. Meteor. Soc., 114, 939-966.

Rottman, J. W., and P. F. Linden, 2001: Gravity currents. Environmental Stratified Flows, Kluwer Academic, 89-117.

San José, R., J. L. Casanova, R. E. Viloria, and J. Casanova, 1985: Evaluation of the turbulent parameters of the unstable surface boundary layer outside Businger's range. Atmos. Environ., 19, 1555-1561.

Scinocca, J. F., and N. A. McFarlane, 2000: The parameterization of drag induced by stratified flow over anisotropic orography. Quart. J. Roy. Meteor. Soc., 126, 2353-2393.

Simpson, J. E., 1969: A comparison between laboratory and atmospheric density currents. Quart. J. Roy. Meteor. Soc., 95, 758-765.

_ 1982: Gravity currents in the laboratory, atmosphere, and ocean. Annu. Rev. Fluid Mech., 14, 213-234.

— 1997: Gravity Currents in the Environment and the Laboratory. Cambridge University Press, 244 pp.

, and P. F. Linden, 1989: Frontogenesis in a fluid with horizontal density gradients. J. Fluid Mech., 202, 1-16.

Stewart, R. W., 1969: Turbulence and waves in a stratified atmosphere. Radio Sci., 4, 1269-1278.

Stull, R. B., 1988: An Introduction to Boundary Layer Meteorology. Kluwer Academic, 666 pp.

Tennekes, H., 1976: Fourier-transform ambiguity in turbulence dynamics. J. Atmos. Sci., 33, 1660-1663.

Terradellas, E., and D. Cano, 2007: Implementation of a singlecolumn model for fog and low cloud forecasting at central Spanish airports. Pure Appl. Geophys., 164, 1327-1345.

— - G. Morales, J. Cuxart, and C. Yagüe, 2001: Wavelet methods: Application to the study of the atmospheric boundary layer under non-stationary conditions. Dyn. Atmos. Oceans, 34, 225-244.

— R. M. Soler, E. Ferreres, and M. Bravo, 2005: Analysis of oscillations in the stable atmospheric boundary layer using wavelet methods. Bound.-Layer Meteor., 114, 489-518.

Thyer, N. H., 1966: A theoretical explanation of mountain and valley winds by a numerical method. Arch. Meteor. Geophys. Bioklimatol., 15, 318-348.

Torrence, C., and G. Compo, 1998: A practical guide to wavelet analysis. Bull. Amer. Meteor. Soc., 79, 61-78.

Uccellini, L. W., and S. E. Koch, 1987: The synoptic setting and possible energy sources for mesoscale wave disturbances. Mon. Wea. Rev., 115, 721-729.

Van Gorsel, E., R. Vogt, A. Christen, and M. Rotach, 2003: Lowfrequency temperature and velocity oscillations in katabatic winds. Proc. Int. Conf. on Alpine Meteorology, Brig, Switzerland, WMO. [Available online at http://www.map.meteoswiss.ch/mapdoc/icam2003/579.pdf.]

Viana, S., C. Yagüe, G. Maqueda, and G. Morales, 2007: Study of the surface pressure fluctuations generated by waves and turbulence in the nocturnal boundary layer during SABLES 2006 field campaign. Física Tierra, 19, 55-71. [Available online at http://revistas.ucm.es/fis/02144557/articulos/FITE0707110055A. PDF.] 
— E. Terradellas, C. Yagüe, and G. Maqueda, 2008: Analysis of the different regimes of atmospheric turbulence observed during a single night. Nuovo Cimento C Geophys. Space Phys., 31, 723-742.

, C. Yagüe, and G. Maqueda, 2009: Propagation and effects of a mesoscale gravity wave over a weakly-stratified nocturnal boundary layer during the SABLES2006 field campaign. Bound.-Layer Meteor., 133, 165-188.

Vickers, D., and L. Mahrt, 2003: The cospectral gap and turbulent flux calculations. J. Atmos. Oceanic Technol., 20, 660-672.

Voronovich, V., and G. Kiely, 2007: On the gap in the spectra of surface-layer atmospheric turbulence. Bound.-Layer Meteor., 122, 67-83.
Wilczac, J. M., S. P. Oncley, and S. A. Stage, 2001: Sonic anemometer tilt correction algorithms. Bound.-Layer Meteor., 99, $127-150$.

Yagüe, C., and J. M. Redondo, 1995: A case study of turbulent parameters during the Antarctic winter. Antarct. Sci., 7, 421-433.

_- S. Viana, G. Maqueda, M. F. Lazcano, G. Morales, and J. M. Rees, 2007: A study on the nocturnal atmospheric boundary layer: SABLES2006. Física Tierra, 19, 37-53. [Available online at http://revistas.ucm.es/fis/02144557/articulos/ FITE0707110037A.PDF.]

Zammett, R. J., and A. C. Fowler, 2007: Katabatic winds on ice sheets: A refinement of the Prandtl model. J. Atmos. Sci., 64, 2707-2716. 